\title{
Increasing the church's relevance and impact in poor-resource areas by adding sexual reproductive health to missional activities
}

\author{
Margaret Lynne Dockinga \\ a Director, Wise Choices for Life reproductive health training workshops, Uganda
}

To be relevant in the world today, the church must prioritise sexual reproductive health and family planning. The church's silence about God's creation of our sexuality needs to be broken; it is an essential part of our calling.

For most of my life, maternal mortality was a statistic not a reality. As a midwife for 30 years in Australia, arriving in Uganda nearly ruined me as I faced the high incidence of teenage maternal deaths.

The turning point came six months into my two-year internship with African Enterprise Uganda. I had become a registered midwife with the Ugandan nurse's board and was volunteering on a weekly basis teaching students at the Government Regional Referral Hospital in Jinja. There was no privacy, linen, or supportive fathers. The Ugandan women were stoic, and without much fuss the babies arrived. However, the day that three women required an emergency caesarean, one of them a very young girl, changed my direction in life.

The midwife on duty continued without stress, in spite of complicated cases arriving endlessly. The doctor arrived, confirmed obstructed labour in all three and said he would operate when they had money to pay for sterile gloves, sutures, and IV fluids. Tears and sickness welled up in me and all my work seemed a waste of time. Not one of these women was prepared with the resources to pay for their lifesaving operation.

According to the Ugandan Demographic Health Survey (2011), one in four girls between the ages of 15 and 19 have had a baby or is currently pregnant. The average fertility rate in rural Uganda is seven children per mother, which often results in haemor- rhages, a major cause of maternal death. ${ }^{1}$ The three women that day were facing tragic results: death, stillbirth, or life with a vesico-vaginal or recto-vaginal fistula. Fistulas occur where the foetal head creates pressure on the urethra and/or the bowel leading to necrosis, and leakage of urine and faeces through the vagina. These are common in very young girls whose pelves are not yet capable of birth, leading to incontinence, shame, and isolation.

Because of their immature physiological development, adolescents are more likely to experience complications during delivery than older women. ${ }^{2}$ In many societies, the mistaken assumption is made that the onset of menses signals reproductive maturity.

That day I knew I was being called from the birthing unit to move into the community setting, to warn future mothers and fathers about the causes of maternal deaths. I believed if I could involve male religious leaders, who held more influence in the community than midwives, to understand prevention strategies, we could prevent more maternal deaths. Fortunately, I did not have to wait long for my first opportunity.

\section{Bringing midwifery out of the clinic and into the community}

Northern Uganda is perhaps mostly known for its conflicts and the terror organisation Lord's Resistance Army (LRA) led by Joseph Kony. The missionary living there invited me to share God's design for sexuality with 60 women from the border of Uganda and South Sudan. These women were from various faiths, and I immediately recognised it 
as an opportunity to put my growing conviction into practice. Can we find ways to mix faith, science, and traditional practices in a way that leads to reduced maternal deaths?

I started with God's amazing story of creative love with the meeting of the sperm and ovum, pregnancy, birth, menstrual cycle and fertile days, and finally family planning methods. After two days, the women were angry. They asked me why they had not been told this good news about their bodies before. One of them said, "We now know why you white women don't have so many babies. We want this also." They continued on, "Where have you been?!" and "When are you coming to all our villages to tell everyone?" The missionary admitted afterwards that she had never been taught this subject in Bible school. The women were rightfully angry. In Faith Matters International Family Planning from a Christian Perspective, we can read the following:

There are an estimated 222 million women in less-developed countries who experience this unmet need (of family planning). If these women have access to family planning methods and unmet need is addressed, it would prevent 26 million abortions, 79,000 maternal deaths, and 1.1. million infant deaths. ${ }^{3}$

\section{The role of the church in family planning}

Back at Jinja, I stayed at a Christian vocational institute where male and female students were segregated by locking the dormitories at 7:30 in the evening, to prevent unwanted pregnancies. I was asked to do random pregnancy checks on the girls, and if positive they were told to leave. The nurse admitted that no one could talk to the girls or boys, as staff were ignorant and reluctant to talk about sexuality. This helped me see that we, the church, also battle ignorance and reluctance about sexual reproductive health.
Many of the talks to youths are focused on fear and immoral behaviours. With teenagers dying from abortions, perforated uteruses, or haemorrhages, we must dare to admit that fear tactics and silence do not work. We have missed the opportunity to talk with truth and courage about God's wonderful creation of true love, faithfulness, sexuality, and pregnancy, which must now include how to control our fertility using the latest research. We have not been holistic in addressing the challenges of the real world.

To reduce poverty, the church globally needs to be equipped to effectively communicate God's creation of our sexuality and add that into their current ministry. The local church is one of the best places to deliver lifesaving messages about spirituality and sexuality. Which Bible colleges train pastors and youth workers in the wonderful story of the menstrual cycle, puberty, and how babies are made?

\section{Involving men and community leaders}

In most developing countries, it is the male political or religious leaders that have the greatest power and influence. We want to see a shift toward equal value for women but we cannot afford to wait for that change. To the international community, this is old news. In the UN report from the 1994 Interna-

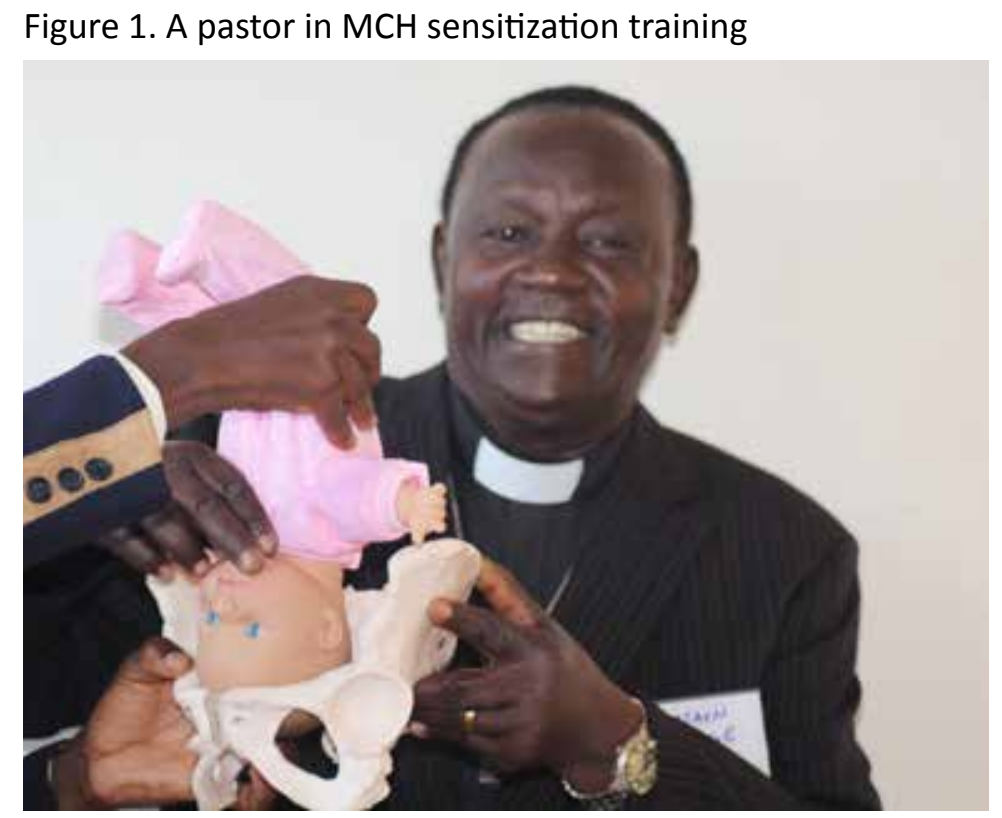


tional Population and Development conference, we can read the following:

Special efforts should be made to emphasize men's shared responsibility and promote their active involvement in responsible parenthood, sexual and reproductive behaviour, including family planning; prenatal, maternal and child health; prevention of sexually transmitted diseases, including HIV; prevention of unwanted and high-risk pregnancies; shared control and contribution to family income, children's education, health, and nutrition; and recognition and promotion of the equal value of children of both sexes. $^{4}$

We must face the facts and make sexual reproductive health our new frontier in mission. The church needs training in how to talk to men about sex, pregnancy, childbirth, and family planning, and not leave this to overworked midwives in hospital settings.

\section{A change of approach: Wise Choices for Life}

Driven by my experiences and encouraged by Dr. David Cummings, past president of Wycliffe Bible Translators International and now senior trainer at Leadership Matters, I designed a creative, interactive curriculum, and it was endorsed by the Ugandan Ministry of Health in 2015. Use of the manual Life Skills by the U.S. Peace Corps (Publication MOO63, 2001, used with permission) was a helpful start.

The final curriculum integrates:

- principles of the Christian faith to provide and care for all children. (I Tim 3:12 and 5:8),

- the Ugandan culture, and

- God's creation for us to be sexual beings.

It has a positive focus on God's design for true love, commitment, and faithfulness.
The training is implemented by the Ugandan people under the capable leadership of Mrs. Joyce Kidulu, our regional coordinator based in Eastern Uganda.

Ultimately, the goals of this training are to contribute to:

- better health outcomes for women,

- fewer unplanned pregnancies, orphans, and abandoned babies,

- manageable family sizes, and

- increased respectful relationships and parenting skills.

The "train the trainer model" includes practical skills in communication, drama, and leading debates. It aims to create safe spaces for respectful discussions around culture, faith, traditions, and discerning myths and truths about our bodies. The lessons include:

- our value and worth as children of God,

- puberty,

- the miracle of birth,

- maternal mortality,

Figure 2. A man in $\mathrm{MCH}$ sensitization training

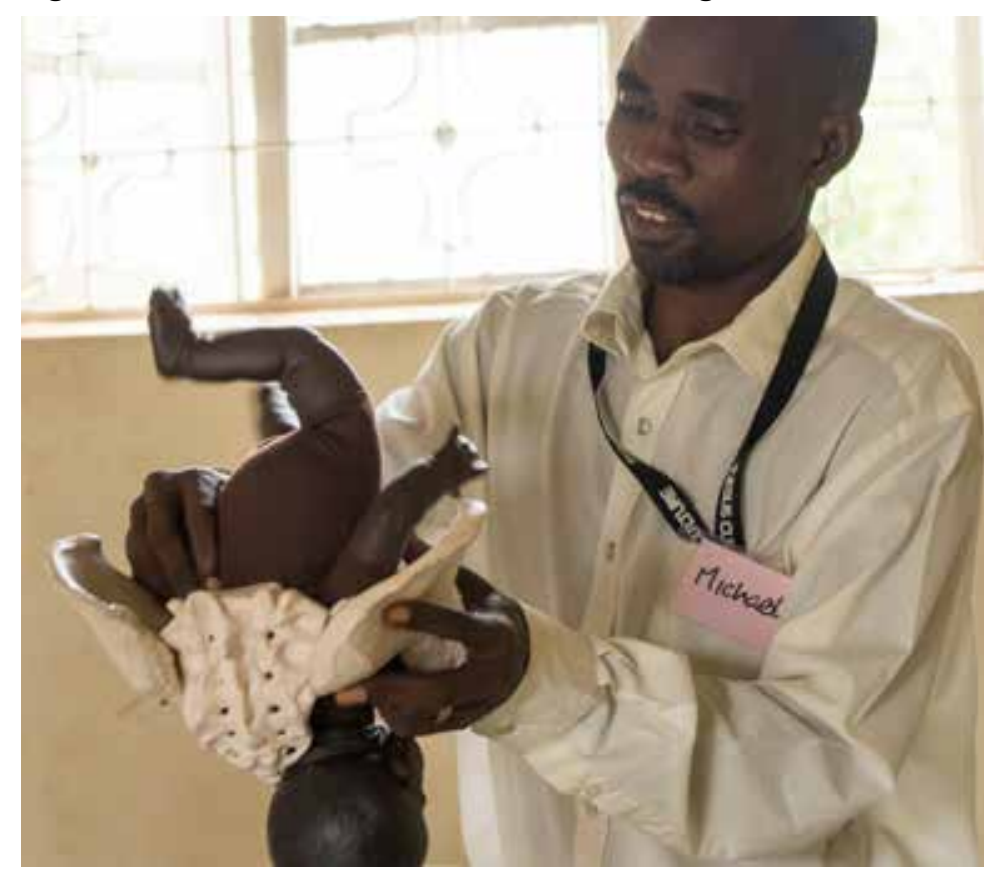


- advantages of abstinence,

- parenting, family planning, and rights of children,

- HIV,

- population growth and the environment, and

- gender-based violence and rape.

This curriculum, called Wise Choices for Life (WCFL), is now used in Uganda in a variety of settings - Uganda Christian University, youth groups, prisons, and schools. WCFL has also been endorsed by the Uganda Christian University, the Ministry of Health, and the archbishop of Uganda, Stanley Ntagali. He writes, "The church of Uganda recognises this manual and the Wise Choices for Life program as a unique opportunity to equip youth all over the world with knowledge on sexual reproductive health, family planning, maternal child health, and HIV/AIDS within the context of their families and environment." 5

The demand for training grows in Uganda, and is an opportunity for churches to disciple youths holistically. As a church, we should be a voice for the vulnerable but not at the expense of their decision-making power. Withholding lifesaving scientific knowledge perpetuates the poverty trap and makes us moral policemen, not disciples of men. If we deem family planning good enough for ourselves, why neglect to empower others with the same options?

To be truly Christ-like in a broken world, we need to add reproductive health into missional training schools. Youths who are ignorant of the science of human reproduction become vulnerable to sexual exploitation. The church and mission-training institutions need to change their approach and equip youths with knowledge and life skills to make wise decisions in life. Life skills include choosing safe relationships, ensuring effective communication, and practising critical thinking combined with discussions around faith and traditional customs. This is creating a shift in thinking regarding the traditional need to have many children, starting very young, and continuing till menopause.

The success in Uganda has led to requests from Ethiopia, Tanzania, and Kenya. The Board of WCFL in Australia has been encouraged by the growth and we have begun the registration process as a non-government organisation in Uganda. This is a step toward real ownership of the training and will over time lead to less dependency on Australia. It is an exciting time as we see transformation and a shift in thinking around such traditions as child marriage and producing large families that has led to many obstetric fistula-led maternal deaths and poverty.

Breaking the silence around God's creation of our sexuality is part of our calling. We need a global united voice that empowers whole communities. It is time for us to change. I now know that the tragic experiences in the hospital labour wards were not in vain. The result of the initial 2-day training with the 60 women in Northern Uganda started me on a new curriculum development path that now reaches the male leaders in local churches, and supports and cares for women's wellbeing and saves their lives. To save the mothers we need to reach the men with the amazing story of God's creation so evident in childbirth.

Our next international training conference is at Kampala in November. www.wisechoicesforlife. org/kampala-conference 


\section{References}

1 Uganda Bureau of Statistics, MEASURE DHS, ICF International. Uganda demographic and health survey, 2011. 2012. August: $67 \& 58$. Available from: https://dhsprogram.com/pubs/pdf/FR264/FR264.pdf

2 Zabin LS, Kiragu K. The health consequences of adolescent sexual and fertility behaviour in sub-Saharan Africa. Studies in Family Planning. June 1998. 29(2):210-32. https://doi.org/10.2307/172160

3 Huber D, Wilson A, Pirzadeh P, Funna S, Bormet M, Orange, $\mathrm{M}$, et. al. Faith matters - international family planning from a Christian perspective. Christian Connections for International Health. 2015: 6. Available from: http:// www.ccih.org/Faith-Matters-FP-Christian-Perspective.pdf

4 United Nations. Programme of action adopted at the international conference on population and development, Cairo, $20^{\text {th }}$ Anniversary Edition. New York: United Nations Population Fund (UNFPA). 2014: 37.

5 Statement from the archbishop of the Church of Uganda. June 2015.

Peer Reviewed

Competing Interests: None declared.

Correspondence: Margaret Lynne Docking, marg@wisechoicesforlife.org

Cite this article as: Docking ML. Increasing the church's relevance and impact in poor-resource areas by adding sexual reproductive health to missional activities. Christian Journal for Global Health. July 2017; 4(2):95-99; https://doi.org/10.15566/cjgh.v4i2.173.

(C) Docking ML. This is an open-access article distributed under the terms of the Creative Commons Attribution License, which permits unrestricted use, distribution, and reproduction in any medium, provided the original author and source are properly cited. To view a copy of the license, visit http://creativecommons.org/licenses/by/4.0/ 